\title{
Diagnostic accuracy of Endoscopic Trimodal Imaging and Chromoendoscopy for lesion characterization in ulcerative colitis surveillance: ETMI or chromoendoscopy for lesion characterization in colitis
}

\author{
J.L.A. Vleugels', M.D. Rutter ${ }^{2,3}$, K. Ragunath', ${ }^{4}$, C.J. Rees ${ }^{3,5}$, C.Y. Ponsioen', C. Lahiff ${ }^{6}$, S.N. Ket ${ }^{6}$, L.K. \\ Wanders' ${ }^{1}$, S. Samuel ${ }^{4}$, F. Butt ${ }^{5}$, T. Kuiper', S.P.L Travis ${ }^{6}$, G. D’Haens' ${ }^{1}$, L.M. Wang ${ }^{7}$, S. van Eeden ${ }^{8}$, a J.E. \\ East ${ }^{6}$ and ${ }^{\mathrm{a}} \mathrm{E}$. Dekker $^{1}$
}

aBoth authors contributed equally in conception, design and monitoring of the study and are cosenior authors.

${ }^{1}$ Department of Gastroenterology and Hepatology, Academic Medical Centre, Amsterdam ${ }^{2}$ Tees Bowel Cancer Screening Centre, University Hospital of North Tees, Stockton-on-Tees Cleveland, United Kingdom

${ }^{3}$ Newcastle University, Newcastle-upon-Tyne, United Kingdom

${ }^{4}$ Nottingham Digestive Diseases Centre, University of Nottingham and NIHR Biomedical Research Centre, Nottingham University Hospitals NHS Trust, Nottingham, United Kingdom

${ }^{5}$ Department of Gastroenterology, South Tyneside District Hospital, Tyne and Wear, United Kingdom ${ }^{6}$ Translational Gastroenterology Unit, and Oxford NIHR Biomedical Research Centre, John Radcliffe Hospital, University of Oxford, United Kingdom

${ }^{7}$ Departmernt of Cellular Pathology, John Radcliffe Hospital, University of Oxford, United Kingdom ${ }^{8}$ Department of Pathology, Academic Medical Centre, Amsterdam

\section{CORRESPONDING AUTHORS:}

Evelien Dekker

Academic Medical Center

Cancer Center Amsterdam

Department of Gastroenterology and Hepatology

Meibergdreef 9

1105 AZ Amsterdam, the Netherlands

e.dekker@amc.uva.nl

\author{
James E. East \\ Translational Gastroenterology Unit \\ Experimental Medicine Division \\ University of Oxford \\ John Radcliffe Hospital \\ Headley Way \\ Headington \\ Oxford, United Kingdom \\ james.east@ndm.ox.ac.uk
}

KEYWORDS: Sensitivity and specificity, Ulcerative colitis, surveillance/screening, colonoscopy, dysplasia, image-enhanced endoscopy, optical diagnosis, sessile serrated lesion

ABBREVIATIONS: ulcerative colitis (UC), colorectal cancer (CRC), chromoendoscopy (CE), Autofluorescence imaging (AFI), primary sclerosing cholangitis (PSC), high-definition white light endoscopy (HD-WLE), Boston Bowel Preparation Score (BBPS), sessile serrated lesion (SSL), confidence intervals (Cls), Flexible spectral Imaging Color Enhancement (FICE).

AUTHORS CONTRIBUTION: Trial design: M.D. Rutter, K. Ragunath, C.J. Rees, L.K. Wanders, T. Kuiper, S. van Eeden, J.E. East and E. Dekker. Patient recruitment: J.L.A. Vleugels, M.D. Rutter, K. Ragunath, C.J. Rees, C.Y. Ponsioen, C. Lahiff, S.N. Ket, L.K. Wanders, S. Samuel, F. Butt, S.P.L. Travis, G. D'Haens, 
J.E. East and E. Dekker. Data collection: all authors. Data analysis and interpretation: J.L.A. Vleugels, J.E. East and E. Dekker. Writing of manuscript: J.L.A. Vleugels, J.E. East and E. Dekker. All authors reviewed the final manuscript for important intellectual content and agreed to submit.

\section{DECLARATION OF INTEREST:}

JV reports grants and non-financial support from Olympus Europe, during the conduct of the study. $M R$ reports grants and non-financial support from Olympus Keymed, during the conduct of the study. $K R$ reports grants and non-financial from Olympus Keymed, during the conduct of the study; personal fees from Olympus Keymed and Olympus Europe, outside the submitted work. CR reports grants and non-financial from Olympus Keymed, during the conduct of the study; grants, personal fees and other from NORGINE and ARC medical, non-financial support from Boston, outside the submitted work. CP reports grants and non-financial support from Olympus Europe, during the conduct of the study. $\mathrm{CL}$ reports grants and non-financial support from Olympus Keymed, during the conduct of the study. SK reports grants and non-financial support from Olympus Keymed, during the conduct of the study. LW reports grants and non-financial support from Olympus Europe, during the conduct of the study. SS reports grants and non-financial support from Olympus Keymed, during the conduct of the study. FB reports grants and non-financial support from Olympus Keymed, during the conduct of the study. TK reports grants and non-financial support from Olympus Europe, during the conduct of the study. ST reports grants and non-financial support from Olympus Keymed, during the conduct of the study; personal fees from Abbvie, Bristol Myers Squibb, Cosmo technologies, Genentech, Guiliani, Takeda, Pfizer, Shire Pharma, NPS, Proximagen, VHSquared, Topivert, Ferring Pharmaceuticals, Celgene, Glaxo Smith Kline, Amgen, Biogen, Enterome, Immunocore, Immunometabolism, Bioclinica, Boerrhinger Ingelheim, Gilead, Grunenthal, Janssen, Novartis, Celgene, Receptos, PharmOlam, SigmoidPharma, Theravance, and grants from Ferring, Abbvie, Schering-Plough, Merck Sharpe \& Dhome, Procter \& Gamble, Warner Chilcott, Lilly, UCB, Vifor outside the submitted work. GDH reports grants and nonfinancial support from Olympus Europe, during the conduct of the study; grants and personal fees from AbbVie, grants and personal fees from Medtronic, personal fees from Ablynx, personal fees from Boehringer-Ingelheim, personal fees from Celgene, personal fees from Celltrion, personal fees from Galapagos NV, grants and personal fees from Pfizer, grants and personal fees from Takeda, grants and personal fees from Johnson and Johnson, personal fees from Gilead, personal fees from Topivert, personal fees from Immunic, personal fees from Robarts Clinical Trials, grants and personal fees from Prometheus Laboratories, personal fees from Eli Lily, grants and personal fees from GSK, outside the submitted work. LMW reports grants and non-financial support from Olympus Keymed, during the conduct of the study. SVE reports grants and non-financial support from Olympus Europe, during the conduct of the study. JE reports grants and non-financial support from Olympus Keymed, during the conduct of the study; reports personal fees from Lumendi, from Boston Scientific, outside the submitted work. ED reports grants, personal fees and non-financial support from Olympus Europe, during the conduct of the study; grants, personal fees and non-financial support from FujiFilm, personal fees from Tillots, outside the submitted work.

FUNDING: Olympus Europe and Olympus Keymed provided research equipment on loan for this study, Olympus Europe and Olympus Keymed provided an unrestricted research grant for this study and had no involvement in the design, recruitment, data collection, analysis or interpretation of writing of the manuscript. J.E. East and S.P.L. Travis were supported by the National Institute for Health Research (NIHR) Oxford Biomedical Research Centre (BRC). K. Ragunath and S. Samuel were 
supported by the National Institute for Health Research (NIHR) Nottingham Biomedical Research Centre (BRC). The views expressed are those of the author(s) and not necessarily those of the NHS, the NIHR or the Department of Health.

WORD COUNT: 3,494 (3,500 max)

\section{ABSTRACT (250/250)}

Background: Patients with longstanding ulcerative colitis (UC) are at increased risk for developing CRC. During surveillance colonoscopy, a variety of dysplastic and non-dysplastic lesions are detected. The 
aim of this study was to address the diagnostic accuracy of endoscopic differentiation autofluorescence imaging (AFI), narrow band imaging (NBI) and chromoendoscopy (CE).

Methods: This is a pre-specified additional analysis of a multicentre randomised controlled trial that compared AFI with CE for dysplasia detection in 210 patients with longstanding UC (FIND-UC trial). In the AFI arm, endoscopists recorded AFI color and Kudo pit pattern using NBI. Kudo pit pattern was described in the $\mathrm{CE}$ arm. For $\mathrm{AFI}$, purple colour and ambiguous colour combined with pit pattern type III-V on NBI was considered dysplastic. For pit pattern description using NBI and CE, type III-V was considered dysplastic. Histology was the reference standard; sessile serrated lesions without dysplasia were considered non-dysplastic.

Results: In total, 52 dysplastic and 255 non-dysplastic lesions were detected. Overall sensitivity for real-time prediction of dysplasia was $76.9 \%$ (95\% confidence interval (CI) 46.2-95.0) for NBI and AFI combined, and $81.6 \%(95 \% \mathrm{Cl} 65.7-92.3)$ for $\mathrm{CE}(\mathrm{p}=0.72)$. For high confidence predictions, negative predictive value (NPV) of the combination of AFI and NBI was $97.7 \%$ (95\% Cl 92.4-99.3) versus $97.4 \%$ (95\% Cl 90.2-97.2) for CE $(p=0.41)$.

Interpretation: Sensitivity for endoscopic differentiation of dysplastic lesions detected during surveillance of patients with longstanding UC seems limited. The high NPV using these techniques may be sufficient to leave suspected non-dysplastic lesions in situ without biopsy (NTR4062). 


\section{Introduction}

Patients with longstanding ulcerative colitis (UC) are at increased risk for developing colorectal cancer (CRC). ${ }^{1,2}$ As it is believed that CRC in patients with longstanding UC develops gradually from chronically inflamed mucosa to dysplasia to CRC, surveillance colonoscopies are recommended to detect dysplasia in a timely manner. ${ }^{3}$ Colonoscopic surveillance reduces CRC incidence and mortality, in part due to early detection of dysplasia. ${ }^{4}$ Chromoendoscopy (CE), which uses application of topical dye on the mucosa to highlight subtle differences, with targeted biopsies of visible lesions, is currently recommended as surveillance strategy as it has consistently been shown to increase dysplasia detection rates. ${ }^{5-7}$ However, apart from detecting dysplastic lesions, a variety of non-dysplastic lesions is detected during surveillance. These non-dysplastic lesions comprise post-inflammatory polyps, lesions caused by ongoing chronic active inflammation or scarring, and the more common hyperplastic lesions.

Several endoscopic imaging techniques have been studied regarding their ability to differentiate dysplastic from non-dysplastic mucosa in patients with longstanding colitis. Besides $\mathrm{CE}$, ${ }^{8-12}$ these include advanced imaging techniques as i-S $\operatorname{can}^{10}$, autofluorescence imaging (AFI), ${ }^{13}$ narrow band imaging (NBI) ${ }^{8,13-15}$ and confocal laser endomicroscopy $(\mathrm{CLE}){ }^{16,17} \mathrm{It}$ is important to differentiate between dysplastic and non-dysplastic lesions endoscopically as only dysplastic lesions need to be removed to prevent CRC development. ${ }^{18}$ In an ideal situation, endoscopic determination as to whether a lesion is dysplastic or not dysplastic should have a high sensitivity combined with a high negative predictive value for predicting dysplastic histology. This would imply that all dysplastic lesions are identified by endoscopic diagnosis and that lesions confidently characterised as non-dysplastic can be left in situ without biopsy or resection.

The aim of the current study was to assess AFI, NBI and CE for their accuracy to characterize dysplastic and non-dysplastic lesions in patients with longstanding UC. 


\section{Methods}

Study design

This study was a pre-specified additional analysis of the FIND-UC trial ("an international multicenter randomised controlled trial of chromoendoscopy versus autoFluorescence Imaging for Neoplasia Detection in patients with longstanding Ulcerative Colitis"). The FIND-UC trial was a randomised controlled parallel trial in which dysplasia detection rates of AFI and CE were compared to determine whether AFI should be further investigated as a dysplasia surveillance method in patients with longstanding UC (Netherlands Trial Register number 4062). Methods and outcomes of this trial are described in detail elsewhere. ${ }^{19}$ The Standards for Reporting of Diagnostic Accuracy (STARD) guideline was followed in reporting the diagnostic test accuracies of all modalities with respect to differentiation. ${ }^{20}$

\section{Patients}

Patients with longstanding ulcerative colitis scheduled for dysplasia surveillance at one of five participating academic medical centres in the UK and the Netherlands were consecutively approached for participation in the FIND-UC trial. Patients were eligible for inclusion in this trial if they were 18 years and older and had longstanding UC, which was defined as left-sided colitis (Montreal E2) at least 15 years or pancolitis (Montreal E3) at least 8 years. ${ }^{21}$ Patients were excluded prior to colonoscopy if they were unable to provide informed consent, had noticed a change of bowel habit in the two months prior to the surveillance colonoscopy, were referred for evaluation of an earlier detected lesion (or refused surgery), were unfit to undergo surveillance colonoscopy, had a proven genetic predisposition for CRC development, used anticoagulant drugs or had a coagulation disorder which precluded taking biopsies. Prior to randomizing during the study procedure, discontinuation criteria included a Boston Bowel Preparation Scale $22<6$ and/or active colitis ${ }^{23}$ assessed during intubation. Active colitis was defined as a Mayo colitis score $>1$ in the proximal (cecum and ascending), transverse or distal (descending, sigmoid and rectum) colon. ${ }^{23}$

\section{Endoscopists and endoscopic equipment}

At each participating centre, two endoscopists participated in the study. At the start of the study, all endoscopists were required to have performed at least 20 colonoscopies with the endoscopic equipment in patients with longstanding UC. All participating endoscopists attended a one-day clinical teaching session, in which CE and AFI were discussed in detail and a hands-on colonoscopy was performed. The training also included a presentation of multiple dysplastic and nondysplastic lesions detected by AFI or CE in patients with longstanding UC. 
Colonoscopies were performed using the Lucera Elite video processor system with sequential red-green-blue illumination (CV-H260; Olympus Medical Systems Co., Tokyo, Japan) and CFH240AZL/I colonoscopes (Olympus Medical Systems Co., Tokyo, Japan). The system contained three different imaging modes; AFI, NBI and high-definition white light. Switching between the imaging modes was performed by pressing a button on the shaft of the colonoscope. High-definition monitor output was used for both arms placed at appropriate viewing distances at the discretion of the endoscopist.

\section{Study procedure}

Patients were randomised upon reaching the caecum to determine whether AFI or CE was used during extubation. Randomization was minimised for previous dysplasia and concomitant primary sclerosing cholangitis. When patients were randomised for AFI, the imaging mode was switched to AFI. When randomised to CE, segmental pancolonic spraying of $0.1 \%$ methylene blue or $0.3 \%$ indigo carmine was performed before inspection. ${ }^{24}$ During withdrawal from the caecum or terminal ileum, the colon was scrutinised for the presence of lesions, mucosal irregularities, ulcers, and strictures. If a lesion was detected, the segment of the colon was recorded (caecum, ascending, transverse, descending, sigmoid, rectosigmoid colon or rectum), the size was estimated by using a reference of known diameter e.g. open biopsy forceps, and the morphology of the lesion was described according to the Paris classification. ${ }^{25}$

\section{Real-time lesion characterization (index test)}

When AFI was used for scrutinizing the colon, the colour of the lesion was recorded (purple, ambiguous, green). When a lesion was detected using AFI, the imaging mode was switched to NBI to record the Kudo pit pattern (type I-V). ${ }^{26}$ When patients were randomised to CE during extubation, the Kudo pit pattern (type I-V) classification was used to classify the lesion, including a level of confidence (high or low) for the endoscopic diagnosis. Per detected lesion, confidence levels for the endoscopic diagnosis were recorded and endoscopists were asked on which imaging mode they had based their endoscopic diagnosis. In patients with more than 3 post-inflammatory or hyperplastic polyps, biopsies were taken of a maximum of three of these lesions per patient and only those with an aberrant aspect on $\mathrm{AFI}, \mathrm{NBI}$, or white light were biopsied.

\section{Histopathology (reference test)}

All lesions were collected in separate histology containers. Initial histological assessment was performed by pathologists with expertise in gastrointestinal pathology in each centre, who were blinded to the endoscopic assessments. All dysplastic cases were centrally reviewed by a second 
specialist pathologist in the UK and the Netherlands to confirm initial findings. To further strengthen initial histopathology results, a random $10 \%$ of all histological samples were centrally reviewed by a specialist pathologist blinded to the initial diagnosis. Initial histological assessment and histology review was performed according to the revised Vienna guidelines. ${ }^{27}$ Sessile serrated lesions (SSLS) were defined as serrated lesions with at least two adjacent or three irregular distributed, dilated or horizontally branched crypts with an ' $\mathrm{L}$ ' or inverted ' $T$ '. ${ }^{28}$

\section{Study outcomes}

The primary outcome of this study was the diagnostic test accuracy (e.g. sensitivity, specificity, positive and negative predictive values) of $\mathrm{AFI}, \mathrm{NBI}$ and $\mathrm{CE}$ for the endoscopic characterization of dysplastic lesions in patients with longstanding UC.

Secondary outcomes included a comparison between the endoscopic characterization based on the combination of AFI and NBI versus the endoscopic characterization based on CE of detected lesions in the FIND-UC trial; a description of detected dysplastic and non-dysplastic lesions; identification of endoscopic factors associated with dysplastic lesions; and a description of endoscopic differentiation of SSLS.

\section{Statistical analysis}

Diagnostic test accuracies were calculated by comparing the endoscopic characterization of $\mathrm{CE}, \mathrm{AFI}$ and NBI with the outcomes of histopathology. Histopathological outcomes of dysplasia were considered the reference standard. Dysplastic histology was defined as cancer, adenomas and SSLS diagnosed with dysplasia, and other histology specimens containing dysplasia. Histopathology outcomes indefinite for dysplasia and SSLs without dysplasia were considered non-dysplastic. For AFI, purple was considered dysplastic, while green was considered non-dysplastic. Lesions with ambiguous color on AFI and Kudo pit pattern type I-II were also considered non-dysplastic. For endoscopic characterization with Kudo pit pattern using NBI and CE, Kudo pit pattern type III-V was considered dysplastic. If real-time lesion characterization (index test) or histopathology outcome (reference test) was missing, these were excluded from the analysis.

Univariate logistic regression analysis with dysplasia (yes or no) as outcome was performed to identify predictive endoscopic factors associated with dysplasia. Predictive factors included in the model were location of the lesion (distal versus proximal to the descending colon), location in a part of colon that was currently or previously inflamed (yes or no), endoscopic size (in mm), polypoid (Paris morphology Is, Isp and Ip) versus non-polypoid (Paris morphology Ila, Ilb and IIc), clear margins (yes 
or no) and Kudo pit pattern classification determined with either NBI or CE (Kudo I-II versus Kudo IIIV). All predictive factors were combined in a multivariate logistic regression model.

For all outcomes on diagnostic test accuracies, 95\% confidence intervals (Cls) were calculated. Diagnostic test accuracies of the combined endoscopic characterization based on AFI and NBI versus endoscopic characterization using CE were compared with Chi-square test. Outcomes of multivariate logistic regression analysis to identify factors associated with dysplasia were presented as odds ratios including its 95\% Cls. SPSS Version 24.0 (IBM SPSS Statistics for Windows, Armonk, New York, USA) was used for analysis. Diagnostic test accuracies were calculated in R version 3.4.3 (R Foundation for Statistical Computing, Vienna, Austria) using the EpiR package. A $p$-value $<0.05$ was considered statistically significant. 


\section{Results}

Between August $1^{\text {st }} 2013$ and March $10^{\text {th }} 2017,105$ patients were randomised for inspection with AFI and 105 with CE. Baseline characteristics of these patients are shown in table 1. In total, 312 lesions were detected in the 210 patients included in this trial (flowchart 1 ).

\section{Diagnostic test accuracies for lesion characterization using AFI, NBI and CE}

When AFI was used during extubation, all detected lesions were characterised with both AFI and NBI (figure 1). When CE was used during extubation, Kudo pit pattern analysis was performed (figure 2). Diagnostic test accuracies per imaging modality are shown in table 2 . The original $2 \times 2$ contingency tables including high confidence predictions are shown in supplementary material 1.

For AFI, the overall accuracy of real/time lesion characterization was $76.3 \%$ and $77.3 \%$ for pitpattern analysis with NBI. Combining lesion characterization of NBI and AFI increased overall accuracy to $88.8 \%$. When lesions were detected with $\mathrm{AFI}$, endoscopists based their endoscopic characterization on $\mathrm{AFI}, \mathrm{NBI}$ or white light in $33.3 \%, 45.0 \%$ and $20.7 \%$ of lesions, respectively. The overall accuracy of CE for lesion characterization was $\mathbf{8 6 . 7 \%}$. High confidence predictions were associated with more accurate histology prediction when AFI and NBI (OR 5.23, 95\% Cl 1.45-18.81), and CE was used (OR $4.05,95 \% \mathrm{Cl} 1.90-8.62)$.

Sensitivity for dysplasia of $\mathrm{AFI}, \mathrm{NBI}$ and the combined endoscopic characterization of the endoscopist was $91.7 \%, 53.9 \%$ and $76.9 \%$, respectively. Sensitivity of high-confidence predictions of the endoscopist based on both AFI and NBI was $80.0 \%$ (table 2). The sensitivity of characterizing dysplastic lesions using CE for Kudo pit pattern analysis was $81.6 \%$, and $88.5 \%$ for high confidence predictions.

The negative predictive value for high-confidence characterizations of dysplastic histology was 97.7\% when AFI and NBI were combined, and $97.4 \%$ for high-confidence predictions using CE.

\section{Lesion characteristics}

Of 312 detected lesions, 52 (16.7\%) contained dysplasia. Clinicopathologic features of detected lesions are shown in table 3. Dysplastic lesions had a mean size of $5.5 \mathrm{~mm}( \pm 5.7)$, were predominantly (66.7\%) located proximal to the descending colon and the majority (66.7\%) had flatelevated (Paris Ila) or flat (Paris IIb) morphology. Sixty-six percent of dysplastic lesions were detected in a part of the colon that was previously inflamed.

Outcomes of univariate and multivariate logistic regression analysis for defining endoscopic features associated with dysplasia are shown in table 4. Dysplastic lesions were more likely to be located proximal to the descending colon (OR $2.23,95 \% \mathrm{Cl} 1.01-4.90$ ), endoscopically classified as 
having non-polypoid morphology ( $\mathrm{OR} 2.59,95 \% \mathrm{Cl} 1.15-5.82)$ and described with Kudo pit pattern type III-V with NBI or CE (OR 11.54, 95\% Cl 5.17-25.76).

Endoscopic characterization of SSLS

Of 18 detected SSLS, most were located proximal to the descending colon (78\%) and flat or flat-elevated (Paris Ila or IIb) morphology was seen in $83 \%$ of SSLs. Using AFI during extubation, four SSLs were detected. Two of these were endoscopically diagnosed as post-inflammatory polyps. AFI colour was described as purple (50\%) or green (50\%). Using NBI for Kudo pit pattern description, type II and type IIIs (for the two expected post-inflammatory polyps) were described. All were confidently predicted to be non-dysplastic. Using CE for inspection, 14 SSLs were detected. Type II pit pattern was described in $100 \%$ of SSLs. 


\section{Discussion}

We compared $\mathrm{AFI}$ and $\mathrm{CE}$ for dysplasia detection in a parallel prospective randomised trial in 210 patients with longstanding UC and assessed real-time lesion characterization using AFI, NBI and $\mathrm{CE}$. In this additional analysis, lesion characterization using $\mathrm{AFI}, \mathrm{NBI}$ and $\mathrm{CE}$ resulted in sensitivities of $91.7 \%, 53.8 \%$ and $81.6 \%$, respectively. The negative predictive values for high confidence predictions of dysplasia using $\mathrm{AFI}, \mathrm{NBI}$ and $\mathrm{CE}$ were $98.6 \%, 92.8 \%$ and $97.5 \%$, respectively. Combining the findings of $\mathrm{AFI}$ and $\mathrm{NBI}$ resulted in an overall sensitivity of $71.4 \%$ and a negative predictive value of real-time high-confidence predictions of $97.7 \%$. There were no significant differences between the combination of AFI and NBI and using CE for real-time lesion characterization. Endoscopic characteristics associated with dysplastic lesions were proximal location, non-polypoid morphology (Paris Ila-Ilb) and Kudo pit pattern type III-V defined with NBI or CE. Out of 18 detected SSLs, 2 were described as having Kudo pit pattern IIIs.

To our knowledge, we are the first to compare $\mathrm{AFI}, \mathrm{NBI}$ and $\mathrm{CE}$ for real-time lesion characterization in patients with longstanding UC. In a previous study of van den Broek et al., lesion characterization using AFI and NBI was recorded. ${ }^{13}$ In this study, sensitivity for AFI, NBI and the two modalities combined was $100 \%, 75 \%$ and $100 \%$. Negative predictive value for real-time dysplasia prediction was only reported for evaluation of Kudo pit pattern using NBI and was $94 \%$. Comparing these data with the results of our study, we found a lower sensitivity for real-time dysplasia prediction of $\mathrm{AFI}, \mathrm{NBI}$ and the combination of the two. Two retrospective studies have shown that $38-86 \%$ of dysplastic lesions have a purple color on AFI. ${ }^{29,30}$ This may imply that using AFI colour alone for realtime diagnosis would not identify all dysplastic lesions. Non-magnifying NBI for real-time prediction of dysplasia has been assessed in two other studies; sensitivity for dysplasia using NBI for Kudo pit pattern analysis was $42 \%$ and $76 \%$, respectively. ${ }^{14,31}$ Negative predictive values were $88 \%$ and $95 \%$, respectively. Non-magnifying CE has also been studied for real-time dysplasia prediction; sensitivities and negative predictive values range between $32-93 \%, 88-98 \%$ respectively. ${ }^{9,} 10,32$ All these values correspond to the sensitivities and negative predictive values for real-time dysplasia predictions using $\mathrm{AFI}, \mathrm{NBI}$ or CE that we report in the current study.

In a recently published image-analysis study, NBI and CE were compared for differentiation between dysplastic and non-dysplastic lesions using the Kudo pit pattern, assessed by ten specialist endoscopists. ${ }^{8}$ Sensitivity for CE for Kudo pit pattern diagnosis of dysplasia was significantly higher compared to NBI ( $88 \%$ vs. $60 \%, p<0.01$ ). The negative predictive values for Kudo pit pattern analysis of both techniques were similar ( $89 \%$ vs. $89 \%, p=0.74)$. Inter-observer agreement was higher for diagnosis of dysplasia using NBI than with $\mathrm{CE}$, but the overall agreement between specialist endoscopists was only moderate to substantial. This low inter-observer agreement in differentiating 
dysplastic from non-dysplastic lesions has also been reported in another image-based study. ${ }^{33}$ The results of these studies emphasise that there is considerable disagreement in optical diagnosis of dysplasia by specialist endoscopists using several advanced imaging techniques. It is likely that this can be extrapolated to general endoscopy practice. Moreover, there seems to be no preferred imaging technique for differentiating dysplastic from non-dysplastic lesions in patients with longstanding UC. Lastly, CLE, which has been exclusively investigated in academic centers, is an imaging technique that provides magnified images of gastrointestinal epithelium comparable to histopathology. Although promising, reported diagnostic accuracies are variable between studies and CLE should therefore be considered as a complementary tool to histopathology instead of replacement of histopathology. ${ }^{16,17}$

Apart from endoscopic diagnosis of Kudo pit pattern, several other endoscopic features seem to be associated with a lesion being dysplastic in patients with longstanding UC. In this study we showed that proximal location and non-polypoid morphology (Paris Ila, Ilb and IIc) were associated with dysplasia. Carballal et al. showed similar findings in a large prospective cohort study of 1,000 patients with longstanding UC, in that proximal located lesions were also more likely to be dysplastic. ${ }^{9}$ Contrary to our findings, these authors showed that lesions with a polypoid morphology (Paris Ip, Isp and Is) were associated with dysplastic histology. A possible explanation for this difference could be the suboptimal inter-observer agreement in describing polyp morphology using the Paris classification. ${ }^{34}$ Altogether, these endoscopic features can contribute to dysplasia differentiation in patients with longstanding UC, so should be considered alongside the Kudo pit pattern classification.

In the average risk population, the serrated neoplasia pathway has been increasingly acknowledged as an independent pathway to CRC development. ${ }^{35}$ In this pathway, SSLs are considered the main precursor lesions. Previous studies reported that some CRCs may be attributed to the serrated neoplasia pathway in inflammatory bowel disease. ${ }^{36-38}$ Moreover, patients with SSLs seem to have a higher risk of synchronous dysplasia and may be at increased risk of developing future visible dysplasia. ${ }^{39,40}$ Therefore, detecting SSLs at colonoscopy seems of importance. In the current study, AFI detected 4 SSLs; 2 were green on AFI and had Kudo type II pit pattern on NBI. Using CE, type II pit pattern was described in $100 \%$ of SSLS. As endoscopic recognition of SSLs by Kudo pit pattern alone seems difficult, we suggest that all proximal polyps that appear serrated are removed or biopsied, because these may be SSLs. However, given the scarce evidence of the serrated neoplasia pathway in patients with colitis, future studies should investigate to what extent the serrated pathway is involved in CRC development in inflammatory bowel disease. ${ }^{41}$

The main limitation of our study is that all lesions were assessed during endoscopy by specialist endoscopists with an interest in performing endoscopy research. This may have caused selection bias, as it is unclear how less experienced endoscopists would have performed. However, 
based on previous literature we anticipate that if differentiation proves difficult amongst specialists, this can be extrapolated to endoscopists with less experience in optical diagnosis of lesions detected during patients with longstanding UC. Although the Kudo pit pattern classification has been used in several studies for lesion characterization in patients with longstanding UC, it should be noted that the Kudo pit pattern classification is not specifically designed to be used in inflammatory bowel disease or with NBI. Furthermore, the number of dysplastic lesions assessed per single endoscopist participating in our study was quite small. Only 14 evaluated with AFI and NBI, and 38 with CE. Findings of our study should therefore be confirmed in larger sample studies performed in daily clinical practice.

The results of our study further emphasize that despite advanced imaging techniques, specialist endoscopists have difficulty in accurately identifying dysplastic lesions. On the other hand, the high negative predictive values for high confidence predictions show that endoscopists were highly accurate in excluding dysplastic lesions. This implies that the specialist endoscopist, when using advanced imaging techniques such as AFI, NBI, or CE during dysplasia surveillance, is confident that a lesion is not dysplastic; this lesion can be left in situ, without biopsy. For general endoscopy practice, we therefore recommend that typical post-inflammatory polyps with pit pattern type I, or hyperplastic appearing lesions assessed with high levels of confidence can be left without resection or biopsy. But in case of any doubt, we recommend that lesions are removed entirely. If direct endoscopic removal appears difficult or impossible, we recommend taking biopsies for histological assessment. In line with the SCENIC recommendations, the endoscopic management of detected lesions is principally based on the resectability of these lesions. ${ }^{42}$ For endoscopists performing dysplasia surveillance in inflammatory bowel disease patients, training programs for lesion differentiation should be developed and validated. Furthermore, high quality photo-documentation should be taken in case of doubt, to enable feedback and discussion with other endoscopists.

Even with multiple advanced imaging techniques like AFI, high-definition NBI, or highdefinition $\mathrm{CE}$, specialist endoscopists cannot reliably identify dysplastic lesions encountered during surveillance in patients with longstanding UC. However, when specialist endoscopists are confident that a lesion is benign, the probability of a lesion being dysplastic is minimal. This emphasizes the value of pathological assessment of all potentially dysplastic lesions that are encountered during colonoscopy surveillance in patients with longstanding UC. Lesions confidently considered nondysplastic may be left without biopsy. Future studies should assess whether the results of optical diagnosis by specialist endoscopists in this study can be extrapolated to general endoscopy practice. 

Table 1. Patient and colonoscopy characteristics

\begin{tabular}{|l|l|l|}
\hline & AFI (N=105) & CE (N=105) \\
\hline Mean age, years ( \pm SD) & $56.3( \pm 13.1)$ & $56.1( \pm 12.3)$ \\
\hline Male gender, $\mathrm{n}(\%)$ & $61(58.1 \%)$ & $61(58.1 \%)$ \\
\hline UC duration in years, median (IQR) & $22.5(15.0-32.8)$ & $19.0(13.0-27.3)$ \\
\hline Extent of colitis, n (\%) & & \\
\hline \multicolumn{1}{|c|}{ Pancolitis (Montreal E3) } & $68(64.8 \%)$ & $74(70.5 \%)$ \\
\hline \multicolumn{1}{|c|}{ Left-sided (Montreal E2) } & $37(35.2 \%)$ & $31(29.5 \%)$ \\
\hline Previous dysplasia, $\mathrm{n}(\%)$ & $16(15.2 \%)$ & $18(17.1 \%)$ \\
\hline Concomitant PSC, $\mathrm{n}(\%)$ & $18(17.1 \%)$ & $20(19.0 \%)$ \\
\hline Dysplasia detected, $\mathrm{n}(\%)$ & $13(12.4 \%)$ & $20(19.0 \%)$ \\
\hline $\begin{array}{l}\text { Mean number } \text { of detected dysplastic } \\
\text { lesions, } \mathrm{n}( \pm \text { SD) }\end{array}$ & $0.13( \pm 0.34)$ & $0.37( \pm 1.02)$ \\
\hline Negative colonoscopies*, $\mathrm{n}(\%)$ & $55(52.4 \%)$ & $36(34.2 \%)$ \\
\hline
\end{tabular}

*colonoscopies without targeted biopsies, $\mathrm{AFI}=$ autofluorescence imaging, $\mathrm{CE}=$ chromoendoscopy, $\mathrm{SD}=$ standard deviation, $\mathrm{UC}=$ ulcerative colitis, $\mathrm{IQR}=$ interquartile range, $\mathrm{PSC}=$ primary sclerosing cholangitis. 
Table 2. Diagnostic test accuracies calculated using dysplastic lesions as reference standard for endoscopic characterization.

\begin{tabular}{|c|c|c|c|c|c|}
\hline \multicolumn{6}{|c|}{ Overall } \\
\hline & $\begin{array}{l}\text { Accuracy } \\
\%(95 \% \mathrm{Cl})\end{array}$ & $\begin{array}{l}\text { Sensitivity } \\
\%(95 \% \mathrm{Cl})\end{array}$ & $\begin{array}{l}\text { Specificity } \\
\%(95 \% \mathrm{Cl})\end{array}$ & $\begin{array}{c}\text { PPV } \\
\%(95 \% \mathrm{Cl})\end{array}$ & $\begin{array}{c}\text { NPV } \\
\%(95 \% \mathrm{Cl})\end{array}$ \\
\hline AFI & $76.3 \%(67.4-83.8)$ & $91.7 \%(61.5-99.8)$ & $74.5 \%(64.9-82.6)$ & $29.7 \%(22.6-38.1)$ & $98.7 \%$ (92.1-99.8) \\
\hline NBI & $77.3 \%(68.6-84.1)$ & $53.9 \%(25.1-80.8)$ & $80.8 \%$ (71.9-87.8) & $25.9 \%(15.6-39.9)$ & $93.3 \%(88.5-96.2)$ \\
\hline Combination* & $88.8 \%$ (81.6-93.9) & $76.9 \%(46.2-95.0)$ & $90.3 \%(82.9-95.3)$ & $50.0 \%(34.1-65.9)$ & $96.9 \%(92.0-98.8)$ \\
\hline $\mathrm{CE}$ & $86.7 \%(81.0-90.9)$ & $81.6 \%(65.7-92.3)$ & $88.1 \%(81.7-92.9)$ & $64.6 \%(53.2-74.5)$ & $94.7 \%(90.2-97.2)$ \\
\hline $\begin{array}{c}p \text {-value } \\
\text { combination vs. CE }\end{array}$ & 0.84 & 0.72 & 0.78 & 0.13 & 0.41 \\
\hline \multicolumn{6}{|c|}{ High confidence } \\
\hline & $\begin{array}{c}\text { Accuracy } \\
\%(95 \% \mathrm{Cl}) \\
\end{array}$ & $\begin{array}{l}\text { Sensitivity } \\
\%(95 \% \mathrm{Cl}) \\
\end{array}$ & $\begin{array}{l}\text { Specificity } \\
\%(95 \% \mathrm{Cl}) \\
\end{array}$ & $\begin{array}{c}\text { PPV } \\
\%(95 \% \mathrm{Cl}) \\
\end{array}$ & $\begin{array}{c}\text { NPV } \\
\%(95 \% \mathrm{Cl}) \\
\end{array}$ \\
\hline AFI & $80.2 \%(71.2-87.0)$ & $88.9 \%(51.8-99.7)$ & $79.3 \%(69.3-87.3)$ & $30.8 \%(21.7-41.6)$ & $98.6 \%(91.6-99.8)$ \\
\hline NBI & $81.6 \%(72.5-88.7)$ & $70.0 \%$ (34.8-93.3) & $83.0 \%(73.5-90.1)$ & $31.8 \%(20.2-46.3)$ & $96.1 \%(90.4-98.4)$ \\
\hline Combination & $92.0 \%(85.0-95.9)$ & $80.0 \%(44.4-97.5)$ & $93.3 \%(86.1-97.5)$ & $57.1 \%(36.7-75.4)$ & $97.7 \%(92.4-99.3)$ \\
\hline CE & $89.9 \%(84.0-93.8)$ & $88.5 \%$ (69.9-97.6) & $90.2 \%(83.6-94.9)$ & $65.7 \%(52.4-77.0)$ & $97.4 \%(92.7-99.1)$ \\
\hline $\begin{array}{c}\text { p-value } \\
\text { combination vs. CE }\end{array}$ & 0.58 & 0.51 & 0.28 & 0.57 & 0.88 \\
\hline
\end{tabular}

*Endoscopic diagnosis of the endoscopist using AFI and NBI. PPV=positive predictive value, $\mathrm{Cl}=$ confidence interval, NPV=negative predictive value, $\mathrm{AFI}=$ autofluorescence imaging, $\mathrm{NBI}=$ narrow band imaging, $\mathrm{CE}=$ chromoendoscopy 
Table 3. Clinicopathological characteristics of lesions detected by AFI and CE.

\begin{tabular}{|c|c|c|}
\hline & AFI (N = 124) & CE $(N=188)$ \\
\hline \multicolumn{3}{|l|}{ Dysplastic } \\
\hline CRC & - & 1 \\
\hline Adenoma & 13 & 35 \\
\hline HGD & - & 1 \\
\hline LGD & 13 & 34 \\
\hline \multicolumn{3}{|l|}{ Dysplastic mucosa } \\
\hline HGD & - & - \\
\hline LGD & 1 & 2 \\
\hline $\begin{array}{l}\text { Biopsies of surrounding } \\
\text { mucosa containing dysplasia }\end{array}$ & 1 & 1 \\
\hline Proximal location, n (\%) & $13(92.9 \%)$ & $22(57.9 \%)$ \\
\hline Size in mm, mean (SD) & $3.3( \pm 2.4)$ & $6.2( \pm 6.3)$ \\
\hline $\begin{array}{l}\text { Flat (elevated) morphology, } n \\
\text { (\%) }\end{array}$ & $8(57.1 \%)$ & $25(65.8 \%)$ \\
\hline Complete resection*, n (\%) & $11(78.6 \%)$ & $27(71.1 \%)$ \\
\hline \multicolumn{3}{|l|}{ Neoplastic histology } \\
\hline SSL & 4 & 14 \\
\hline ID & - & 3 \\
\hline Non-neoplastic, $n$ & 105 & 129 \\
\hline Hyperplastic, $n$ & 18 & 53 \\
\hline Inflammatory, $\mathrm{n}$ & 41 & 30 \\
\hline Other non-neoplastic, $\mathrm{n}$ & 46 & 46 \\
\hline Proximal location, n (\%) & $39(37.1 \%)$ & 63 (48.5\%) \\
\hline Size in $\mathrm{mm}$, mean $( \pm S D)$ & $5.13( \pm 5.69)$ & $4.24( \pm 3.49)$ \\
\hline $\begin{array}{l}\text { Flat (elevated) morphology, } \mathrm{n} \\
\text { (\%) }\end{array}$ & $38(36.2 \%)$ & $71(54.6 \%)$ \\
\hline Complete resection*, n (\%) & $50(47.6 \%)$ & $84(64.6 \%)$ \\
\hline Missing, $n$ & 1 & 4 \\
\hline
\end{tabular}

*complete resection is defined endoscopically. $\mathrm{AFI}=$ autofluorescence imaging, $\mathrm{CE}=$ chromoendoscopy, $\mathrm{CRC}=$ colorectal cancer, $\mathrm{HGD}=\mathrm{high}$ grade dysplasia, $\mathrm{LGD}=$ low grade dysplasia, $\mathrm{mm}=$ millimeter, $\mathrm{SSL}=$ sessile serrated lesion, ID=indefinite for dysplasia. 
Table 4. Outcomes of multivariate logistic regression analysis to find predictors for dysplastic lesions.

\begin{tabular}{|c|c|c|}
\hline & $\begin{array}{l}\text { Univariate logistic } \\
\text { regression } \\
\text { Odds Ratio }(95 \% \mathrm{Cl})\end{array}$ & $\begin{array}{l}\text { Multivariate logistic } \\
\text { regression } \\
\text { Odds Ratio }(95 \% \mathrm{Cl})\end{array}$ \\
\hline \multicolumn{3}{|l|}{ Location } \\
\hline Distal & Reference & Reference \\
\hline Proximal & $2.05(1.09-3.85)$ & $2.23(1.01-4.90)$ \\
\hline \multicolumn{3}{|l|}{$\begin{array}{l}\text { Located in current or previous inflamed } \\
\text { colon segment }\end{array}$} \\
\hline No & Reference & Reference \\
\hline Yes & $0.57(0.30-1.09)$ & $0.51(0.22-1.17)$ \\
\hline Size & $1.02(0.96-1.07)$ & $1.01(0.94-1.07)$ \\
\hline \multicolumn{3}{|l|}{ Morphology } \\
\hline Polypoid* & Reference & Reference \\
\hline Non-polypoid** & $1.82(0.97-3.4)$ & $2.59(1.15-5.82)$ \\
\hline \multicolumn{3}{|l|}{ Margins } \\
\hline Clear & Reference & Reference \\
\hline Not clear & $0.66(0.28-1.51)$ & $0.71(0.24-2.16)$ \\
\hline \multicolumn{3}{|l|}{ Kudo classification with NBI or CE } \\
\hline Type I-II pit pattern & Reference & Reference \\
\hline Type III-V pit pattern & $11.33(5.60-22.94)$ & $11.54(5.17-25.76)$ \\
\hline
\end{tabular}

*Polypoid was defined as Paris classification Ip, Isp and Is. ${ }^{* *}$ Non-polypoid was defined as Paris classification Ila and IIb. NBI=narrow band imaging, $\mathrm{CE}=$ chromoendoscopy 
Flowchart 1. STARD flowchart of lesion differentiation

$\mathrm{CRC}=$ colorectal cancer 
Figure 1. Dysplastic lesion with purple color on AFI (1a) and Kudo IIIS/L pit pattern on NBI (1b). Nondysplastic inflammatory mucosa with purple color on AFI (1c) and Kudo type I pit pattern on NBI (1d). 
Figure 2. Dysplastic lesion with Kudo IV pit pattern on CE (fig 1a). Sessile serrated lesion with Kudo type II pit pattern on CE (fig 1b). Hyperplastic polyp with Kudo type II pit pattern on CE (fig 1C). Inflammatory lesion with Kudo type IIIS/L pit pattern on CE (fig 1d). 


\section{REFERENCES}

1. Bernstein CN, Blanchard JF, Kliewer E, et al. Cancer risk in patients with inflammatory bowel disease: a population-based study. Cancer 2001;91:854-62.

2. Jess T, Rungoe C, Peyrin-Biroulet L. Risk of colorectal cancer in patients with ulcerative colitis: a meta-analysis of population-based cohort studies. Clin Gastroenterol Hepatol 2012;10:639-45.

3. Bernstein CN, Shanahan F, Weinstein WM. Are we telling patients the truth about surveillance colonoscopy in ulcerative colitis? Lancet 1994;343:71-4.

4. Bye WA, Nguyen TM, Parker CE, et al. Strategies for detecting colon cancer in patients with inflammatory bowel disease. Cochrane Database Syst Rev 2017;9:CD000279.

5. Annese V, Daperno M, Rutter MD, et al. European evidence based consensus for endoscopy in inflammatory bowel disease. J Crohns Colitis 2013;7:982-1018.

6. Kaminski MF, Hassan C, Bisschops R, et al. Advanced imaging for detection and differentiation of colorectal neoplasia: European Society of Gastrointestinal Endoscopy (ESGE) Guideline. Endoscopy 2014;46:435-49.

7. Cairns SR, Scholefield JH, Steele RJ, et al. Guidelines for colorectal cancer screening and surveillance in moderate and high risk groups (update from 2002). Gut 2010;59:666-89.

8. Bisschops R, Bessissow T, Dekker E, et al. Pit pattern analysis with high-definition chromoendoscopy and narrow-band imaging for optical diagnosis of dysplasia in patients with ulcerative colitis. Gastrointest Endosc 2017;86:1100-1106.e1.

9. Carballal S, Maisterra S, Lopez-Serrano A, et al. Real-life chromoendoscopy for neoplasia detection and characterisation in long-standing IBD. Gut 2016.

10. Iacucci M, Kaplan GG, Panaccione R, et al. A Randomized Trial Comparing High Definition Colonoscopy Alone With High Definition Dye Spraying and Electronic Virtual Chromoendoscopy for Detection of Colonic Neoplastic Lesions During IBD Surveillance Colonoscopy. Am J Gastroenterol 2017.

11. Nishiyama S, Oka S, Tanaka S, et al. Is it possible to discriminate between neoplastic and nonneoplastic lesions in ulcerative colitis by magnifying colonoscopy? Inflamm Bowel Dis 2014;20:508-13.

12. Hurlstone DP, Sanders DS, Lobo AJ, et al. Indigo carmine-assisted highmagnification chromoscopic colonoscopy for the detection and characterisation of intraepithelial neoplasia in ulcerative colitis: a prospective evaluation. Endoscopy 2005;37:1186-92.

13. van den Broek FJ, Fockens P, van Eeden S, et al. Endoscopic tri-modal imaging for surveillance in ulcerative colitis: randomised comparison of high-resolution endoscopy and autofluorescence imaging for neoplasia detection; and evaluation of narrow-band imaging for classification of lesions. Gut 2008;57:1083-9.

14. Efthymiou M, Allen PB, Taylor AC, et al. Chromoendoscopy versus narrow band imaging for colonic surveillance in inflammatory bowel disease. Inflamm Bowel Dis 2013;19:2132-8.

15. Nishiyama S, Oka S, Tanaka S, et al. Clinical usefulness of narrow band imaging magnifying colonoscopy for assessing ulcerative colitis-associated cancer/dysplasia. Endosc Int Open 2016;4:E1183-e1187.

16. Wanders LK, Kuiper T, Kiesslich R, et al. Limited applicability of chromoendoscopy-guided confocal laser endomicroscopy as daily-practice surveillance strategy in Crohn's disease. Gastrointest Endosc 2016;83:966-71. 
17. Kiesslich R, Goetz M, Lammersdorf K, et al. Chromoscopy-guided endomicroscopy increases the diagnostic yield of intraepithelial neoplasia in ulcerative colitis. Gastroenterology 2007;132:874-82.

18. East JE, Suzuki N, von Herbay A, et al. Narrow band imaging with magnification for dysplasia detection and pit pattern assessment in ulcerative colitis surveillance: a case with multiple dysplasia associated lesions or masses. Gut 2006;55:1432-5.

19. Vleugels JLA, Rutter MD, Ragunath $\mathrm{K}$, et al. Chromoendoscopy versus autofluorescence imaging for neoplasia detection in patients with longstanding ulcerative colitis (FIND-UC): an international, multicentre, randomised controlled trial. Lancet Gastroenterol Hepatol 2018.

20. Bossuyt PM, Reitsma JB, Bruns DE, et al. STARD 2015: an updated list of essential items for reporting diagnostic accuracy studies. Bmj 2015;351:h5527.

21. Silverberg MS, Satsangi J, Ahmad T, et al. Toward an integrated clinical, molecular and serological classification of inflammatory bowel disease: report of a Working Party of the 2005 Montreal World Congress of Gastroenterology. Can J Gastroenterol 2005;19 Suppl A:5A-36A.

22. Calderwood AH, Jacobson BC. Comprehensive validation of the Boston Bowel Preparation Scale. Gastrointest Endosc 2010;72:686-92.

23. Schroeder KW, Tremaine WJ, Ilstrup DM. Coated oral 5-aminosalicylic acid therapy for mildly to moderately active ulcerative colitis. A randomized study. N Engl J Med 1987;317:1625-9.

24. Rutter MD. A practical guide and review of colonoscopic surveillance and chromoendoscopy in patients with colitis. Frontline Gastroenterol 2010;1:126130.

25. The Paris endoscopic classification of superficial neoplastic lesions: esophagus, stomach, and colon: November 30 to December 1, 2002. Gastrointest Endosc 2003;58:S3-43.

26. Kudo S, Tamura S, Nakajima T, et al. Diagnosis of colorectal tumorous lesions by magnifying endoscopy. Gastrointest Endosc 1996;44:8-14.

27. Schlemper RJ, Riddell RH, Kato Y, et al. The Vienna classification of gastrointestinal epithelial neoplasia. Gut 2000;47:251-5.

28. Snover DC AD, Burt RW, Odze RD. Serrated polyps of the colon and rectum and serrated polyposis. in Bosman FT, Carneiro F, Hruban RH, Theise ND (eds): WHO Classification of Tumours of the Digestive System;ed 4. Lyon, IARC, 2010:pp 160165.

29. Yoshioka S, Mitsuyama K, Takedatsu H, et al. Advanced endoscopic features of ulcerative colitis-associated neoplasias: Quantification of autofluorescence imaging. Int J Oncol 2016;48:551-8.

30. Matsumoto T, Nakamura S, Moriyama T, et al. Autofluorescence imaging colonoscopy for the detection of dysplastic lesions in ulcerative colitis: a pilot study. Colorectal Dis 2010;12:e291-7.

31. van den Broek FJ, Fockens P, van Eeden S, et al. Narrow-band imaging versus highdefinition endoscopy for the diagnosis of neoplasia in ulcerative colitis. Endoscopy 2011;43:108-15.

32. Kiesslich $\mathrm{R}$, von Bergh $\mathrm{M}$, Hahn $\mathrm{M}$, et al. Chromoendoscopy with indigocarmine improves the detection of adenomatous and nonadenomatous lesions in the colon. Endoscopy 2001;33:1001-6.

33. Wanders LK, Mooiweer E, Wang J, et al. Low interobserver agreement among endoscopists in differentiating dysplastic from non-dysplastic lesions during 
inflammatory bowel disease colitis surveillance. Scand J Gastroenterol 2015;50:1011-7.

34. van Doorn SC, Hazewinkel Y, East JE, et al. Polyp morphology: an interobserver evaluation for the Paris classification among international experts. Am J Gastroenterol 2015;110:180-7.

35. Ijspeert JEG, Vermeulen L, Meijer GA, et al. Serrated neoplasia-role in colorectal carcinogenesis and clinical implications. Nature Reviews Gastroenterology and Hepatology 2015;12:401-409.

36. Rubio CA, Befrits R, Jaramillo E, et al. Villous and serrated adenomatous growth bordering carcinomas in inflammatory bowel disease. Anticancer Res 2000;20:4761-4.

37. East JE, Atkin WS, Bateman AC, et al. British Society of Gastroenterology position statement on serrated polyps in the colon and rectum. Gut 2017;66:1181-1196.

38. Aust DE, Haase M, Dobryden L, et al. Mutations of the BRAF gene in ulcerative colitis-related colorectal carcinoma. Int J Cancer 2005;115:673-7.

39. Ko HM, Harpaz N, McBride RB, et al. Serrated colorectal polyps in inflammatory bowel disease. Mod Pathol 2015;28:1584-93.

40. Jackson WE, Achkar JP, Macaron C, et al. The Significance of Sessile Serrated Polyps in Inflammatory Bowel Disease. Inflamm Bowel Dis 2016;22:2213-20.

41. Parian AM, Lazarev MG. Serrated Colorectal Lesions in Patients With Inflammatory Bowel Disease. Gastroenterol Hepatol (N Y) 2018;14:19-25.

42. Laine L, Kaltenbach T, Barkun A, et al. SCENIC international consensus statement on surveillance and management of dysplasia in inflammatory bowel disease. Gastrointest Endosc 2015;81:489-501.e26. 